\title{
Slide tracheoplasty in the presence of tracheal bronchus in an infant
}

\author{
Emmanuel Le Bret, MD, PhD, ${ }^{a}$ Natacha Teissier, MD, ${ }^{b}$ Emre Belli, MD, ${ }^{a}$ Anne Sigal-Cinqualbre, MD, ${ }^{c}$ \\ Vincent Couloignier, MD, PhD, ${ }^{\mathrm{b}}$ Philippe Narcy, MD, ${ }^{\mathrm{b}}$ Serge Demontoux, MD, ${ }^{\mathrm{a}}$ Nourredine Gharbi, MD, ${ }^{\text {a }}$ Régine Roussin, ${ }^{\mathrm{a}}$ \\ Thierry Van Den Abbeele, MD, PhD, ${ }^{\mathrm{b}}$ and Alain Serraf, MD, PhD, ${ }^{\mathrm{a}}$ Le Plessis Robinson and Paris, France
}

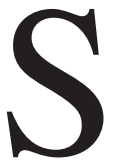

lide tracheoplasty is known to be the gold standard in the management of long-segment tracheal stenosis. ${ }^{1}$ However, in certain situations this operation might become difficult or even impossible for some authors. The frequency of pig bronchus reported in the literature is $0.2 \% .^{2}$ The association of congenital tracheal stenosis and pig bronchus is exceptional. The presence of a tracheal bronchus was considered a relative contraindication to slide tracheoplasty. ${ }^{3}$ We report the case of a child with hypoplasia of the lower half of the trachea associated with a pig bronchus treated with a slide tracheoplasty.

\section{Clinical Summary}

A 4-month-old child weighing $3.8 \mathrm{~kg}$ was referred to our department for a tracheal hypoplasia. She had been intubated for 1 month because of respiratory distress. At admission, the trachea was colonized, and biologic signs of infection were found.

Preoperative assessment. The fibroscopy showed a tracheal stenosis with complete tracheal rings starting at the junction between the first and the second third of the trachea. The smallest fibroscope could not go through the stenosis, and the lower part was not explored. The computed tomographic scan showed hypoplasia of the lower two thirds of the trachea extending to the carina and a pig bronchus emerging from the hypoplastic region that was responsible for the ventilation of the right upper lobe. Echocardiography revealed a partial atrioventricular septal defect with moderate leak of the left atrioventricular valve.

After 1 week of intense antibiotherapy, the tracheal hypoplasia was treated, and decision was made to delay the intracardiac repair because of potential septic risk.

Operative technique. After sternotomy and cervicotomy, the trachea, carina, and main bronchi were dissected. Care was taken to gently dissect the tracheal bronchus, which arose directly from the middle part of the hypoplasia. The suprahyoid insertions were detached.

From the Pediatric Cardio-Thoracic Department ${ }^{\mathrm{a}}$ and the Scanner Department, ${ }^{c}$ Centre Chirurgical Marie Lannelongue, Le Plessis Robinson, France, and the Pediatric ENT Department, ${ }^{\mathrm{b}}$ Robert Debré Hospital, Paris, France.

Received for publication Feb 21, 2006; revisions received March 14, 2006; accepted for publication March 21, 2006.

Address for reprints: Emmanuel Le Bret, MD, PhD, Service des Cardiopathies Congenitales, Centre Chirurgical Marie Lannelongue, 133 Avenue de la Résistance, 92350 Le Plessis Robinson, France (E-mail: e.lebret@ ccml.fr).

J Thorac Cardiovasc Surg 2006;132:e15-6

$0022-5223 / \$ 32.00$

Copyright () 2006 by The American Association for Thoracic Surgery doi:10.1016/j.jtcvs.2006.03.033

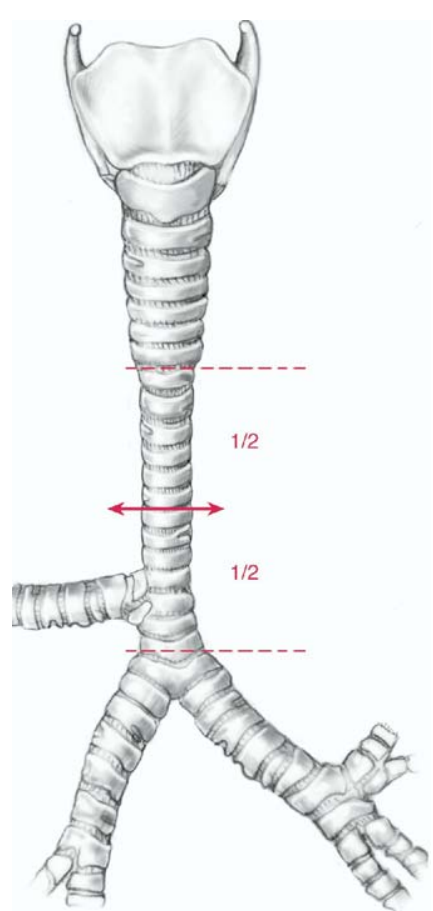

Figure 1. The trachea was transected at the middle part of the hypoplasia above the pig bronchus.

After establishing cardiopulmonary bypass, the trachea was first transected at the middle portion of the hypoplasia above the tracheal bronchus (Figure 1). The proximal end of the hypoplasia was longitudinally sectioned on its posterior part, and the distal end was opened along its anterior part down to the carina. These sections were enlarged asymmetrically, more to the right for the proximal end and more to the left for the distal segment (Figure 2, $A)$. Slide tracheoplasty was then accomplished by sliding the upper part on the lower end (Figure 2,B). Anastomosis was performed with polydioxanone 5-0 and 6-0 sutures. The endotracheal tube was replaced, ventilation was re-established, and the child was weaned from cardiopulmonary bypass.

Preoperative endoscopy showed a nonrestrictive anastomosis, a wide carina, and a nonrestrictive pig bronchus ostium and allowed optimal positioning of the endotracheal tube.

Follow-up. In the absence of bacterial complications, the decision to treat the intracardiac lesion was made on the ninth posttracheal surgery day. Treatment of the partial atrioventricular septal defect was uneventful, and the child was extubated on the 17 th day. 

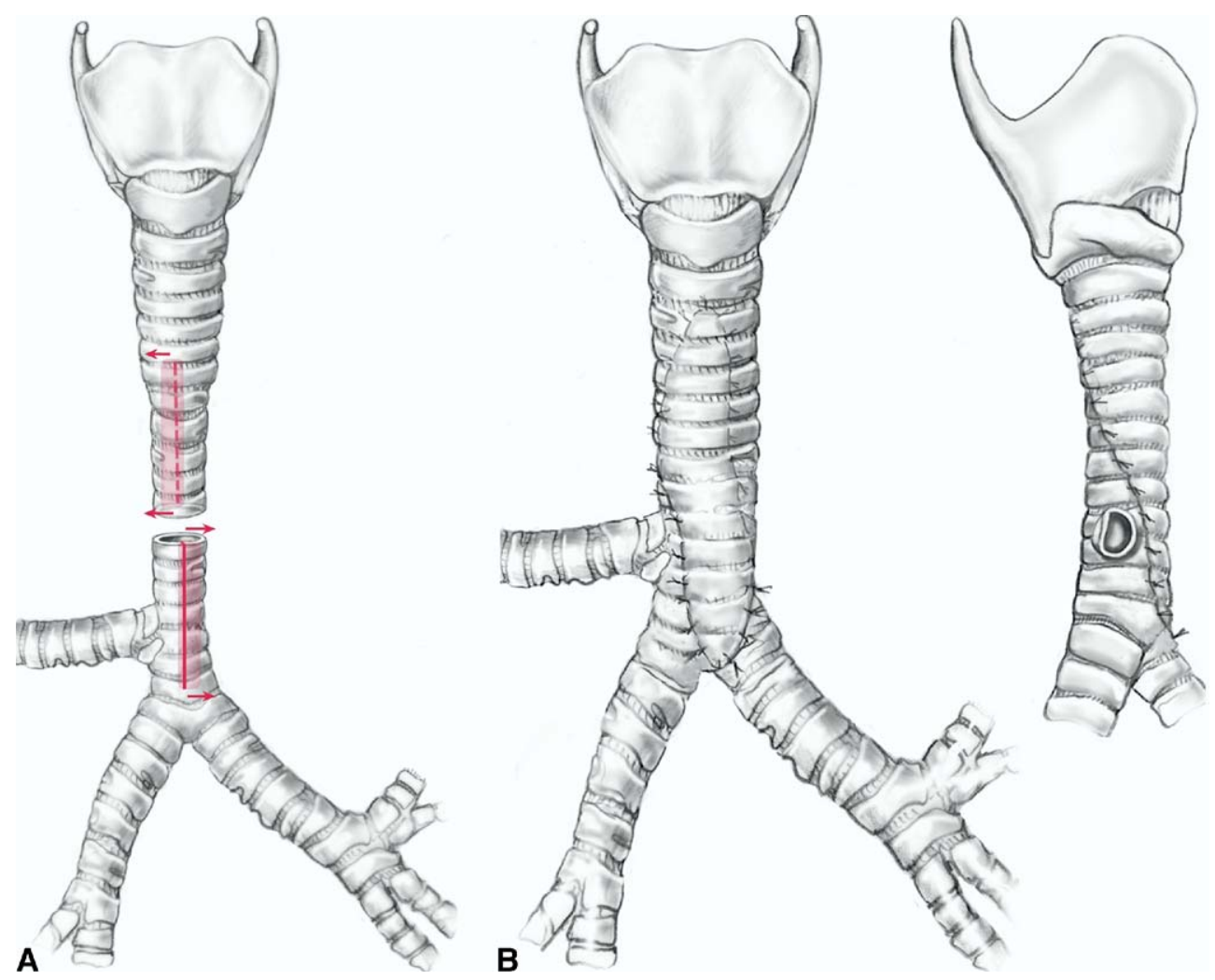

Figure 2. A, Longitudinal sections were enlarged asymmetrically, more to the right for the proximal end and more to the left for the distal segment. B, Slide tracheoplasty was then accomplished.

At discharge, the child was perfectly well, and at 8 months, the last fibroscopy did not show any residual lesion.

\section{Discussion}

The advantages of slide tracheoplasty are well known. ${ }^{1,4}$ However, certain situations, like tracheal bronchus, were considered relative contraindications by some authors. ${ }^{3}$ In these cases tracheal resection with or without bronchus reimplantation ${ }^{5}$ has been reported.

In our experience slide tracheoplasty can be used in such a case, but certain precautions are to be taken.

First, care must be taken to gently dissect the tracheal bronchus, but extensive dissection of the upper segment of the trachea is mandatory to avoid mobilization of the lower segment, which would lead to an angulation of the tracheal bronchus. The upper segment should be brought down to the lower segment and not the opposite.

Second, the tracheal longitudinal incision has to be medial, whereas the enlargement of the trachea has to be made in an asymmetric manner to lay the sutures away from the tracheal bronchus. The tracheal resection of the lower segment should be less important on the side of the tracheal bronchus.
Finally, intraoperative fibroscopy is mandatory to properly position the intubation tube above the pig bronchus.

\section{Conclusion}

In conclusion, the coexistence of tracheal hypoplasia and pig bronchus should not be considered a contraindication to slide tracheoplasty. However, technical care is to be taken.

\section{References}

1. Grillo HC, Wright CD, Vlahakes GJ, McGillivray TE. Management of congenital tracheal stenosis by means of slide tracheoplasty or resection and reconstruction, with long term follow-up of growth after slide tracheoplasty. J Thorac Cardiovasc Surg. 2002;123:145-52.

2. Ghaye B, Szapiro D, Fanchamps JM, Dondelinger RF. Congenital bronchial abnormalities revisited. Radiographics. 2001;21:105-19.

3. Elliott M, Roebuck D, Noctor C, McLaren C, Hartley B, Mok Q, et al. The management of congenital tracheal stenosis. Int J Pediatr Otorhinolaryngol. 2003:67(suppl 1):S183-92.

4. Macchiarini P, Dulmet E, de Montpreville V, Mazmanian GM, Chapelier A, Dartevelle P. Tracheal growth after slide tracheoplasty. J Thorac Cardiovasc Surg. 1997;113:558-66.

5. Loubakov T, Sebening C, Springer W, Hagl S. A case of pulmonary artery sling associated with long-segment funnel trachea and bronchus suis. Ann Thorac Surg. 2004;78:1839-42. 